\title{
Gut-Liver Axis Links Portal Hypertension to Acute-on-Chronic Liver Failure
}

\author{
Jonel Trebicka ${ }^{a, b, c, d}$ Thomas Reibergere, $f$ Wim Lalemang, h \\ a Department of Internal Medicine I, University of Bonn, Bonn, Germany; \\ bEuropean Foundation for the Study of Chronic Liver Failure, Barcelona, Spain; \\ cFaculty of Health Sciences, University of Southern Denmark, Odense, Denmark; \\ dInstitute for Bioengineering of Catalonia, Barcelona, Spain; \\ e Division of Gastroenterology \& Hepatology, Department of Internal Medicine III, Medical University of Vienna, Vienna, Austria; \\ fVienna Hepatic Hemodynamic Laboratory, Medical University of Vienna, Vienna, Austria; \\ g Liver and Biliopancreatic Section, Department of Gastroenterology \& Hepatology, Hospital Gasthuisberg, K.U. Leuven, Leuven, Belgium; \\ h Laboratory of Hepatology, Department Chronic Diseases, Metabolism \& Ageing (CHROMETA), KU Leuven, Leuven, Belgium
}

\section{Keywords}

Portal hypertension - Systemic inflammation .

Acute-on-chronic liver failure, ACLF . Microbiome .

Bacterial translocation

\section{Summary}

Acute-on-chronic liver failure (ACLF) is considered a distinct syndrome in patients with liver disease, with systemic inflammation playing a central role. Portal hypertension (PHT) is also aggravated by inflammation and may subsequently impact the course of ACLF. PHT is more than just an increase in portal pressure in the portal venous system; it aggravates the course of liver disease and, thus, also facilitates the development of acute decompensation and ACLF. A critical mechanistic link between PHT and ACLF might be the gut-liver axis, which is discussed in this review.

(C) 2018 S. Karger GmbH, Freiburg

\section{Introduction}

Advanced chronic liver disease (ACLD, a term that is used similarly to cirrhosis) represents a major cause of morbidity and mortality worldwide [1]. In 2010, cirrhosis was responsible for $1,029,042$ deaths (ca. 2\% of total global deaths) [2]. By 2013 this figure had increased to 1.2 million deaths [3], not taking into account the more than 750,000 liver cancer deaths, mainly as a result of liver cirrhosis [2]. The age-standardized mortality rate of cirrhosis in Europe ranges between 10\% in Western Europe, 18\% in Central Europe and 20\% in Eastern Europe [2]. Acute decompensation (AD) and its progression to acute-on-chronic liver failure (ACLF) are major causes of death due to cirrhosis [4]. Cirrhosis with AD and ACLF are also responsible for 14,544,000 disability-adjusted life years worldwide [2]. Once AD has developed, 15\% of hospitalized patients will further develop ACLF, and of those, $40 \%$ will die within 90 days [5]. ACLF is characterized by the presence of organ failure(s) in acutely decompensated patients [6], but is a very dynamic syndrome with a considerable percentage of patients who do recover [7]. Different predisposing factors (e.g. genetics, epigenetics) and precipitating events (e.g. active alcoholism, infections, bleeding) have been discussed to be involved in the development of $\mathrm{AD}$ and in its progression towards ACLF [5]. The substantial interindividual differences in the predisposition to develop $\mathrm{AD}$ and its progress to ACLF with high mortality remain largely unexplained and form the subject of an ongoing multicenter European study, the PREDICT study (NCT03056612).

In Europe, the main etiology of decompensated cirrhosis is alcoholic liver disease [8]. Probably due to the highly stigmatized status of this etiology, there is a striking imbalance between the burden of cirrhosis and prioritization of treatments and research efforts, which is why they are often overlooked in novel research and treatment foci in universities and hospitals. Interestingly, in 2015, only 7 out of 72 studies worldwide in the field of liver disease investigated cirrhosis and only 1 focused specifically on the syndrome of ACLF [9]. Moreover, as ACLF has been characterized only recently in the CANONIC study [5], optimal management strategies remain to be defined.

\section{KARGER}

() 2018 S. Karger GmbH, Freiburg
Prof. Jonel Trebicka, MD, PhD

Department of Internal Medicine I

University Clinic Bonn

Sigmund-Freud-Str. 25, 53105 Bonn, Germany

jonel.trebicka@efclif.com 


\section{Portal Hypertension and Acute Decompensation}

A hallmark of worsening prognosis in liver cirrhosis is the development of portal hypertension (PHT), mostly referred to as clinically significant portal hypertension (CSPH) [10-12] characterized by a hepatic venous pressure gradient (HVPG) of $\geq 10 \mathrm{~mm}$ $\mathrm{Hg}$. This is defined as increased pressure in the portal vein, the direct vascular connection between the gut (splanchnic organs) and the liver [10-12]. PHT triggers many complications, including development of collaterals (varices) with significant risk for gastrointestinal bleeding, ascites, and hepatic encephalopathy. Importantly, bacterial translocation is increased in the presence of PHT (fig. 1). This is likely related to 2 different mechanisms: On the one hand, venous congestion and splanchnic neoangiogenesis, due to the increased pressure in the portal vein, induce impaired microcirculation and lead to increased permeability in the gut [13]. On the other hand, ascites formation, induced by PHT, seems to be another pathogenic condition of bacterial translocation. Bacterial translocation is of relevance as it is considered one - if not the most - important trigger of AD and ACLF, as it leads to continuous activation of the immune system and chronic systemic inflammation [14-17].

Several direct or indirect consequences of PHT can predispose patients to development of AD and ACLF. Increased abdominal pressure due to ascites or atelectasis of the lung, due to hydrothorax, can facilitate the development of infections such as spontaneous bacterial peritonitis (SBP) or pneumonia, which, together with the increased risk of aspiration in the presence of hepatic encephalopathy (HE), might exacerbate to ACLF with a very poor prognosis [18-21]. However, the hemodynamic derangements in PHT might also predispose to ACLF. Impaired cardiac function (the socalled cirrhotic cardiomyopathy), usually occurring in severe PHT with hyperdynamic circulation, and diminished effective arterial blood volume with consecutive low mean arterial pressure predispose to inadequate cardio-hemodynamic compensatory response after the insult and therefore promote the development of ACLF, as shown for renal failure and hepatorenal syndrome (HRS) in different large retrospective studies [22-24]. Interestingly, a small prospective study from India demonstrated that hemodynamic derangements in cirrhotic patients increase the risk of mortality in ACLF [25]. In these patients, the risk of severe morbidity and mortality after variceal bleeding is considerable and associated with significantly worse outcome [25]. However, variceal hemorrhage no longer represents a major predisposing or precipitating factor for the development of ACLF [5]. A potential reason for this is the successful implementation of BAVENO recommendations for primary [26] and secondary prophylaxis [27] of variceal hemorrhage and adoption of early transjugular intrahepatic portosystemic shunt stent (TIPS) $[28,29]$ strategies in high-risk patients in clinical practice. Thus, optimized management of variceal bleeding has improved the outcome and considerably reduced its contribution as a trigger for ACLF development [28, 29]. Indeed, PHT predisposes and predicts survival in cirrhotic patients. However, while serum biomarkers of chronic inflammation will decrease in most patients after successful TIPS treatment of PHT, these proinflammatory biomarkers remain of independent predictive value for subsequent mortality in cirrhotic patients - even after successful lowering of the portal pressure by TIPS $[17,30]$. Thus, cirrhotic PHT predisposes to ACLF directly through hemodynamic derangements and indirectly through its complications.

\section{Gut-Liver Axis and Liver Diseases}

The gut microbiota and the gut barrier - together with systemic inflammation - and in particular a microbial translocation trigger sustain and further escalate the development of $\mathrm{AD}$ and progression to ACLF $[4,14]$.

The gut microbiota represents the largest pool of genetic material in the body with high metabolic activity. Every human being harbors at least $4 \times 10^{13}$ colonizing microbial cells [31] and more than 10 million non-redundant microbial genes in their gut [32, 33]. There is sufficient evidence that changes in microbiota impact on the progression of liver disease (elegantly summarized in recent reviews [33-35]) and that profound changes in the microbiota occur with the development of liver cirrhosis [36], while underlying mechanisms remain not yet fully explored. There are key players in this interaction, such as an impaired epithelial barrier, in cirrhosis known as 'leaky gut' [33-35], with bacteria or metabolites entering into the portal blood circulation, interacting with immune cells and reaching the hepatic microcirculation, where they interact with nonparenchymal and parenchymal liver cells. The liver also secretes bile acids, which in turn modify the intestinal microbiome and, also, act as signaling molecules between the cirrhotic liver, the gut microbiota, and the intestine [37].

The human microbiota is currently one of the most dynamic research fields and description of functionality and role of the gut microbiome in human health and disease has seen great progress, facilitated by technological and methodological advances [38].

The factors influencing the gut microbiome may be classified into 3 categories: host-intrinsic, host-extrinsic, and environmental. Moreover, the microbiome state feeds back upon itself and, thereby, contributes to compositional variation between individuals. Clearly, these categories overlap and many factors are also associated to each other.

However, the effect size of the different known technical and biological microbiome covariates seem to be in the single digit percent [38]. This could be due to the fact that associations of individual taxa are more relevant than global compositional shifts, or that the gut microbiome's intrinsic ecological dynamics and interactions are largely unknown, in part due to a lack of longitudinal data [38]. Nevertheless, the current total quantification of external factors to microbiome variation is probably in the range of $10-15 \%$ and, thus, of sufficient effect size to be considered in clinical studies, as even some individual factors can confound associations. This likely remains true even if one extends the definition of MWAS to 'microbiome-wide association studies' by also including other data types, such as metatranscriptomic or metabolomic readouts [39]. 


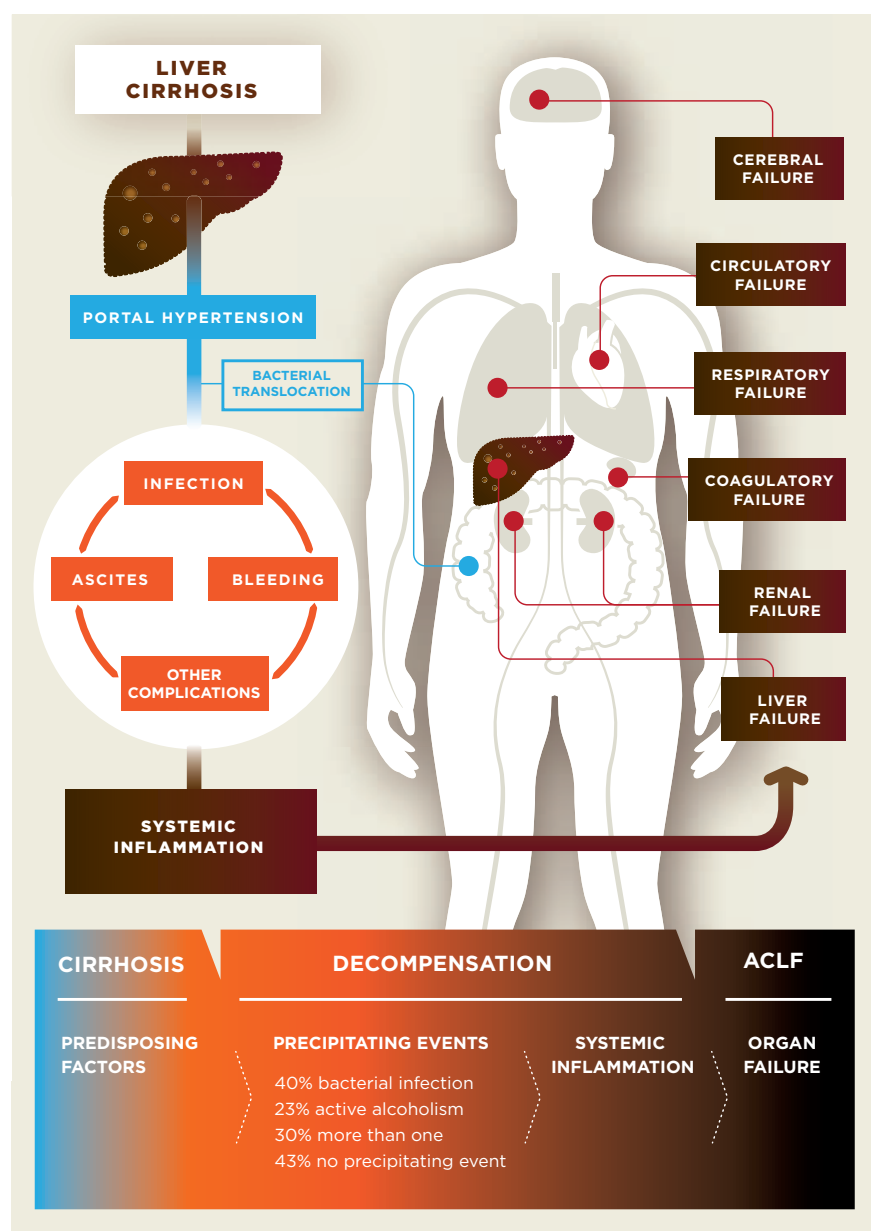

Fig. 1. Complications of liver cirrhosis are mainly due to portal hypertension, while bacterial translocation seems to play an important role as the trigger.

Therefore, microbiome data should be interpreted with great caution. Nevertheless, bacterial translocation is a well-accepted and reproducible process in cirrhosis and has been shown to be an essential driver in the development of complications.

\section{Bacterial Translocation and Systemic Inflammation}

While the etiology of cirrhosis may vary, the microbiome-liver interaction is largely etiology-independent [33]. Only a small percentage (10-30\%) of chronic liver diseases progresses to cirrhosis, but due to its high mortality $[2,3]$ it is of the utmost importance to assess any presence of cirrhosis and PHT - primarily by noninvasive methods, such as transient elastography [40]. At this stage, dysbiosis and bacterial translocation are frequent phenomena, which also determine the development of decompensations in cirrhosis [34], already described in the 1990s [41]. Especially, when PHT is present (increased pressure in the portal vein and the mesenteric veins collecting blood from the splanchnic organs to the liver), complications arise [42]. A TIPS is the most effective treatment of PHT and yet, even after this procedure, many patients de- velop complications of liver disease [43,44], especially due to the spillover of inflammation with resulting development of ACLF as shown by recent data $[5,45,46]$. Additionally, it was found that the presence of ascites, as a sign of decompensation, determines the composition of the circulating microbiome in the portal vein compared to the hepatic vein, right atrium, and peripheral venous blood, and that specific circulating microbiome members correlate with inflammatory markers [47]. It has been established that a specific microbiome phenotype (so-called enterotype) induces pathologies also in hepatic functions [32,33], and that a wide range of microbial effectors (e.g. fungi [48]) may be involved in the development of systemic inflammation.

Systemic inflammation has been shown to cause complications in different chronic diseases. Especially in decompensated liver cirrhosis, it may result in a fatal outcome. The role of systemic inflammation in patients receiving TIPS has been studied in many scenarios [15-17, 45, 49-50]. There is a clear relationship between PHT, hyperdynamic circulation, development of complications, ACLF, and outcome [51]. Interestingly, systemic inflammation can also be reduced by TIPS, underlining the hypothesis that PHT drives systemic inflammation [17, 30, 47, 50]. However, C-reactive protein and white blood cell count may not be suitable early markers of systemic inflammation. In a recent study, patients in which levels of inflammatory markers were higher in the hepatic vein than in the portal vein developed more organ failure and showed a worse outcome [45]. Therefore, while systemic inflammation might be induced by PHT, it persists in some patients even when PHT has been effectively treated and may lead to ACLF.

\section{Decompensation and Response to Treatment}

It is already well accepted that the presence of ascites defines decompensation in patients with liver cirrhosis [52]. However, in patients with decompensated cirrhosis, a subgroup exists with a very high short-term mortality [4]. These patients usually experience acute deterioration of their underlying liver disease, often due to a precipitating illness induced by infection, gastrointestinal bleeding, active alcoholism, or medications. These situations are called $\mathrm{AD}$ episodes and usually require hospital admission [4]. In $15 \%$ of these patients the clinical situation deteriorates and ACLF occurs [5].

In patients with liver cirrhosis and its complications, there are currently no specific strategies to prevent the development of $\mathrm{AD}$ and progression towards ACLF [53]. In general, the treatment options are relatively limited and mostly focus on the symptom rather than the pathogenesis of the liver disease. At this late stage, it is difficult to address the cause of liver injury, as the main focus is to keep the patients alive [53]. Studies have shown that in this collective, a variety of treatment options are needed to treat liver cirrhosis and that the drug response has been very heterogeneous [53]. One reason for these unsatisfactory results might be that the role of the gut microbiome has not been addressed properly. The gut microbiome, apart from its pathogenetic role, possibly also influences 
the effect of medication, either due to the drug metabolism or due to the drug's effect on the microbiome metabolites [54, 55]. Interestingly, $25 \%$ of all nonantibiotic drugs change at least one gut species and this figure is most likely underestimated [56]. To date, in liver cirrhosis there is only 1 study showing the effect of drugs, namely proton pump inhibitors, on gut microbiota changes [57], possibly facilitating the development of alcoholic liver disease. However, the microbiome and its impact on ACLF remains a largely unexplored research area.

\section{Poorly Absorbable Antibiotics as Gut-Liver Axis Intervention}

Whether rifaximin, a poorly absorbable antibiotic, prevents progression in the early stages of alcoholic liver disease is currently under investigation in GALAXY [58].

Several studies have suggested continuous antibiotic treatment as prophylaxis against the development of specific decompensation events, such as SBP, either as primary prophylaxis in specific conditions or as secondary prophylaxis after an episode of SBP [59]. In the specific clinical situation of a variceal bleeding, the prophylactic administration of antibiotics might prevent $\mathrm{AD}$ and ACLF, and it has been shown to improve survival. Here, the use of antibiotics, mainly third-generation cephalosporines and fluoroquinolones, is recommended [59]. Another important issue, which needs to be addressed, is the development of resistance in bacteria in these patients towards widely used antibiotics. Besides these problems, the role of prophylactic treatment in patients with decompensated cirrhosis has been documented once again in a large multicenter trial, which assessed the role of norfloxacin in patient survival [60]. Norfloxacin is a poorly absorbed antibiotic, which is very effective in changing the gut microbiota. Its role was analyzed decades ago in animal models. However, the published data were conflicting, with some studies reporting significant improvement in vascular function and PHT, whereas others did not observe significant effects. Nevertheless, all studies have shown a decrease in bacterial translocation to the mesenteric lymph nodes. While in a recently published, large, randomized placebo-controlled trial the effects of norfloxacin on decompensation and survival were beneficial, many study patients, nevertheless, developed decompensation and died despite norfloxacin administration [61]. In the subgroup analysis, the survival benefit was more pronounced. For the treatment of HE, rifaximin, another poorly absorbed antibiotic, has been approved. Many studies have tested the effect of rifaximin on the progression of liver disease, especially due to alcohol. However, the findings remain unconvincing to date. In some studies, rifaximin showed a major preventive effect $[62,63]$, while in others, this effect could not be determined or was only minor $[64,65]$. Thus, while there is some evidence that some patients might benefit from rifaximin, a better selection and stratification of patients is required in the clinical setting.

\section{Albumin as Attenuation of Inflammation}

Human albumin (HA), an important plasma protein synthesized in the liver, has been used for decades as a marker of liver dysfunction. Parenchymal extinction with progression of fibrosis and liver disease is also associated with hypoalbuminemia, which might play a specific predisposing role in the development of ACLF. During development of AD and progression to ACLF, the quality of HA in liver cirrhosis greatly deteriorates, as shown by the portions of reversibly and irreversibly oxidized HA, which correlate with ACLF grade and survival [46]. Hypoalbuminemia and the quality of albumin contribute to increased cytokine levels and others proinflammatory mediators (e.g. PGE2), which predispose for ACLF in cirrhosis [66-68]. While albumin treatment has been used in different clinical situations for years, the patient benefit remains under discussion. In a small number of scenarios, a clear benefit can be noted, such as in HRS, which basically is a functional renal failure in cirrhosis, in the prevention of HRS when SBP is present, and in the prevention of post-paracentesisinduced circulatory dysfunction $[59,69]$. These scenarios require more or less infusion of HA. Regarding HA administration, adherence to guidelines is good, however, a significant use of albumin outside of recommended indications persists [70]. These data suggest that the 'gut' feeling of clinicians favors the use of albumin and that its use depends on the experience of the clinician adapting the HA treatment to their patient's needs. However, most attempts to prove benefits of HA treatment in other scenarios resulted in controversial findings, and HA in non-SBP infections might not bring any benefit at all [71, 72]. A large trial in Italy evaluating long-term administration of albumin in patients with $\mathrm{AD}$ showed an improvement in survival and a decrease in complications, such as hepatic encephalopathy, renal dysfunction, etc. [73]. Other smaller studies suggest the opposite and have even reported severe adverse events, e.g. pulmonary edema patients with pneumonia, however, albumin administration still prevents HRS and new infections [74]. To date, all attempts to stratify patients have failed and new tools to predict a response to $\mathrm{HA}$ are urgently required, as, on the one hand, it is an expensive and human-derived treatment agent, and, on the other hand, it could lead to complications.

\section{Conclusion}

Development of PHT in chronic liver disease predisposes to development of complications and progression to ACLF. Especially, the gut microbiome and translocation of bacteria and bacterial components (e.g. pathogen-associated molecular patterns (PAMPs)) play an important role in the development of systemic inflammation. These systemic proinflammatory states, aseptic and septic, might persist after efficient treatment of PHT fueling immune dysregulation and further triggering the development of organ failures and thereby ACLF. Microbiome- and inflammationdirected treatments are emerging as promising targets to amelio- 
rate PHT and normalize individual cytokine profiles and specific immune-dysbalanced states in ACLF.

\section{Acknowledgment}

The authors thank S. Dentler for critical reading.

\section{Disclosure Statement}

JT is supported by Deutsche Forschungsgemeinschaft (SFB-TRR57 P18), Cellex Foundation, the European Union's Horizon 2020 Research and Innovation Programme (No. 668031) and Societal Challenges (health, demographic change and well-being (No. 731875)). TR has received grant support by Abbvie, Boehringer-Ingelheim, Gilead, MSD, and Philips Healthcare.

\section{References}

1 de Franchis R; Baveno VI Faculty: Expanding consensus in portal hypertension: report of the Baveno VI Consensus Workshop: stratifying risk and individualizing care for portal hypertension. J Hepatol 2015;63: 743-752.

-2 GBD 2013 DALYs and HALE Collaborators; Murray CJ, Barber RM, Foreman KJ, et al: Global, regional, and national disability-adjusted life years (DALYs) for 306 diseases and injuries and healthy life expectancy (HALE) for 188 countries, 1990-2013: quantifying the epidemiological transition. Lancet 2015;386:21452191.

3 Allen AM, Kim WR: Epidemiology and healthcare burden of acute-on-chronic liver failure. Semin Liver Dis 2016;36:123-126.

4 Arroyo V, Moreau R, Kamath PS, Jalan R, Gines P, Nevens F, Fernandez J, To U, García-Tsao G, Schnabl B: Acute-on-chronic liver failure in cirrhosis. Nat Rev Dis Primers 2016;2:16041.

5 Moreau R, Jalan R, Gines P, Pavesi M, Angeli P, Cordoba J, Durand F, Gustot T, Saliba F, Domenicali M, Gerbes A, Wendon J, Alessandria C, Laleman W, Zeuzem S, Trebicka J, Bernardi M, Arroyo V; CANONIC Study Investigators of the EASL-CLIF Consortium: Acute-on-chronic liver failure is a distinct syndrome that develops in patients with acute decompensation of cirrhosis. Gastroenterology 2013; 144:1426-1437.e9.

6 European Association for the Study of the Liver: EASL Clinical Practice Guidelines for the management of patients with decompensated cirrhosis. J Hepatol 2018;DOI: 10.1016/j.jhep.2018.03.024.

7 Gustot T, Fernandez J, Garcia E, et al; CANONIC Study Investigators of the EASL-CLIF Consortium: Clinical course of acute-on-chronic liver failure syndrome and effects on prognosis. Hepatology 2015;62: 243-252.

8 Mathurin P, Bataller R: Trends in the management and burden of alcoholic liver disease. J Hepatol 2015;62 (suppl 1):S38-46.

9 Zutshi Y: Liver disease treatments: the global market. BBC Research 2015;PHM057C.

10 Tsochatzis EA, Bosch J, Burroughs AK: Liver cirrhosis. Lancet 2014;383:1749-1761.

11 Bosch J, Abraldes JG, Berzigotti A, Garcia-Pagan JC: The clinical use of HVPG measurements in chronic liver disease. Nat Rev Gastroenterol Hepatol 2009;6: 573-582.

12 Ripoll C, Groszmann RJ, Garcia-Tsao G, Bosch J, Grace N, Burroughs A, Planas R, Escorsell A, GarciaPagan JC, Makuch R, Patch D, Matloff DS; Portal Hypertension Collaborative Group: Hepatic venous pressure gradient predicts development of hepatocellular carcinoma independently of severity of cirrhosis. J Hepatol 2009;50:923-928.
13 Reiberger T, Ferlitsch A, Payer BA, Mandorfer M, Heinisch BB, Hayden H, Lammert F, Trauner M, PeckRadosavljevic M, Vogelsang H; Vienna Hepatic Hemodynamic Lab: Non-selective betablocker therapy decreases intestinal permeability and serum levels of LBP and IL-6 in patients with cirrhosis. J Hepatol 2013;58: 911-921.

14 Wiest R, Garcia-Tsao G: Bacterial translocation (BT) in cirrhosis. Hepatology 2005;41:422-433.

15 Trebicka J, Krag A, Gansweid S, Appenrodt B, Schiedermaier P, Sauerbruch T, Spengler U: Endotoxin and tumor necrosis factor-receptor levels in portal and hepatic vein of patients with alcoholic liver cirrhosis receiving elective transjugular intrahepatic portosystemic shunt. Eur J Gastroenterol Hepatol 2011;23: 1218-1225.

16 Trebicka J, Krag A, Gansweid S, Schiedermaier P, Strunk HM, Fimmers R, Strassburg CP, Bendtsen F, Møller S, Sauerbruch T, Spengler U: Soluble TNFalpha-receptors I are prognostic markers in TIPStreated patients with cirrhosis and portal hypertension. PLoS One 2013; 8:e83341.

17 Berres ML, Asmacher S, Lehmann J, Jansen C, Gortzen J, Klein S, Meyer C, Strunk HM, Fimmers R, Tacke F, Strassburg CP, Trautwein C, Sauerbruch T, Wasmuth HE, Trebicka J: CXCL9 is a prognostic marker in patients with liver cirrhosis receiving transjugular intrahepatic portosystemic shunt. J Hepatol 2015;62:332339.

18 Rabe C, Schmitz V, Paashaus M, Musch A, Zickermann H, Dumoulin FL, Sauerbruch T, Caselmann WH: Does intubation really equal death in cirrhotic patients? Factors influencing outcome in patients with liver cirrhosis requiring mechanical ventilation. Intensive Care Med 2004;30:1564-1571.

19 Christou L, Pappas G, Falagas ME: Bacterial infectionrelated morbidity and mortality in cirrhosis. Am J Gastroenterol 2007;102:1510-1517.

20 Bajaj JS, O'Leary JG, Reddy KR, Wong F, Olson JC, Subramanian RM, Brown G, Noble NA, Thacker LR, Kamath PS; North American Consortium For The Study Of End-Stage Liver Disease (NACSELD): Second infections independently increase mortality in hospitalized patients with cirrhosis: the North American consortium for the study of end-stage liver disease (NACSELD) experience. Hepatology 2012;56:23282335.

21 Asrani SK, O'Leary JG: Acute-on-chronic liver failure. Clin Liver Dis 2014;18:561-574.

22 Wong F: Recent advances in our understanding of hepatorenal syndrome. Nat Rev Gastroenterol Hepatol 2012;9:382-391.
23 Bajaj JS, O’Leary JG, Reddy KR, Wong F, Biggins SW, Patton H, Fallon MB, Garcia-Tsao G, Maliakkal B, Malik R, Subramanian RM, Thacker LR, Kamath PS; North American Consortium For The Study Of EndStage Liver Disease (NACSELD): Survival in infectionrelated acute-on-chronic liver failure is defined by extrahepatic organ failures. Hepatology 2014;60:250256.

24 Mandorfer M, Bota S, Schwabl P, Bucsics T, Pfisterer N, Kruzik M, Hagmann M, Blacky A, Ferlitsch A, Sieghart W, Trauner M, Peck-Radosavljevic M, Reiberger T: Nonselective $\beta$ blockers increase risk for hepatorenal syndrome and death in patients with cirrhosis and spontaneous bacterial peritonitis. Gastroenterology 2014;146:1680-1690.el.

25 Garg H, Kumar A, Garg V, Kumar M, Kumar R, Sharma BC, Sarin SK: Hepatic and systemic hemodynamic derangements predict early mortality and recovery in patients with acute-on-chronic liver failure. J Gastroenterol Hepatol 2013;28:1361-1367.

26 Reiberger T, Ulbrich G, Ferlitsch A, Payer BA, Schwabl P, Pinter M, Heinisch BB, Trauner M, Kramer L, PeckRadosavljevic M; Vienna Hepatic Hemodynamic Lab: Carvedilol for primary prophylaxis of variceal bleeding in cirrhotic patients with haemodynamic non-response to propranolol. Gut 2013;62:1634-1641.

27 Pfisterer N, Dexheimer C, Fuchs EM, Bucsics T, Schwabl P, Mandorfer M, Gessl I, Sandrieser L, Baumann L, Riedl F, Scheiner B, Pachofszky T, Dolak W, Schrutka-Kölbl C, Ferlitsch A, Schöniger-Hekele M, Peck-Radosavljevic M, Trauner M, Madl C, Reiberger T: Betablockers do not increase efficacy of band ligation in primary prophylaxis but they improve survival in secondary prophylaxis of variceal bleeding. Aliment Pharmacol Ther 2018;47:966-979.

28 Garcia-Pagan JC, Caca K, Bureau C, Laleman W, Appenrodt B, Luca A, Abraldes JG, Nevens F, Vinel JP, Mössner J, Bosch J; Early TIPS (Transjugular Intrahepatic Portosystemic Shunt) Cooperative Study Group: Early use of TIPS in patients with cirrhosis and variceal bleeding. N Engl J Med 2010;362:2370-2379.

29 Garcia-Pagan JC, Di Pascoli M, Caca K, Laleman W, Bureau C, Appenrodt B, Luca A, Zipprich A, Abraldes JG, Nevens F, Vinel JP, Sauerbruch T, Bosch J: Use of early-TIPS for high-risk variceal bleeding: results of a post-RCT surveillance study. J Hepatol 2013;58:45-50.

30 Berres ML, Lehmann J, Jansen C, Gortzen J, Meyer C, Thomas D, Zimmermann HW, Kroy D, Schumacher F, Strassburg CP, Sauerbruch T, Trautwein C, Wasmuth HE, Trebicka J: Chemokine (C-X-C motif) ligand 11 levels predict survival in cirrhotic patients with transjugular intrahepatic portosystemic shunt. Liver Int 2016;36:386-394.

31 Sender R, Fuchs S, Milo R: Are we really vastly outnumbered? Revisiting the ratio of bacterial to host cells in humans. Cell 2016;164:337-340. 
32 Qin J, Li R, Raes J, et al: A human gut microbial gene catalogue established by metagenomic sequencing. $\mathrm{Na}$ ture 2010;464:59-65.

33 Tilg H, Cani PD, Mayer EA: Gut microbiome and liver diseases. Gut 2016;65:2035-2044

34 Acharya C, Bajaj JS: Gut microbiota and complications of liver disease. Gastroenterol Clin North Am 2017;46: 155-169.

35 Davis BC, Bajaj JS: The human gut microbiome in liver diseases. Semin Liver Dis 2017;37:128-140.

36 Qin N, Yang F, Li A, et al: Alterations of the human gut microbiome in liver cirrhosis. Nature 2014;513: 59-64.

-37 Ridlon JM, Kang DJ, Hylemon PB, Bajaj JS: Gut microbiota, cirrhosis, and alcohol regulate bile acid metabolism in the gut. Dig Dis 2015;33:338-345.

38 Schmidt TSB, Raes J, Bork P: The human gut microbiome: from association to modulation. Cell 2018;172 1198-1215.

-39 Gilbert JA, Quinn RA, Debelius J, Xu ZZ, Morton J, Garg N, Jansson JK, Dorrestein PC, Knight R: Microbiome-wide association studies link dynamic microbial consortia to disease. Nature 2016;535:94-103.

40 Reiberger T, Ferlitsch A, Payer BA, Pinter M, Schwabl P, Stift J, Trauner M, Peck-Radosavljevic M: Noninvasive screening for liver fibrosis and portal hypertension by transient elastography - a large single center experience. Wien Klin Wochenschr 2012;124:395-402.

41 Garcia-Tsao G, Lee FY, Barden GE, Cartun R, West $\mathrm{AB}$ : Bacterial translocation to mesenteric lymph nodes is increased in cirrhotic rats with ascites. Gastroenterology 1995;108:1835-1841.

42 Bosch J, Garcia-Pagan JC: Complications of cirrhosis. I. Portal hypertension. J Hepatol 2000;32:141-156.

43 Trebicka J: Emergency TIPS in a Child-Pugh B patient: when does the window of opportunity open and close? J Hepatol 2017;66:442-450.

44 Trebicka J: Does transjugular intrahepatic portosystemic shunt stent differentially improve survival in a subset of cirrhotic patients? Semin Liver Dis 2018;38: $87-96$.

45 Jansen C, Moller P, Meyer C, Kolbe CC, Bogs C, Pohlmann A, Schierwagen R, Praktiknjo M, Abdullah Z, Lehmann J, Thomas D, Strassburg CP, Latz E, Mueller S, Rössle M, Trebicka J: Increase in liver stiffness after transjugular intrahepatic portosystemic shunt is associated with inflammation and predicts mortality. Hepatology 2018; 67:1472-1484.

46 Claria J, Stauber RE, Coenraad MJ, et al.; CANONIC Study Investigators of the EASL-CLIF Consortium and the European Foundation for the Study of Chronic Liver Failure (EF-CLIF): Systemic inflammation in decompensated cirrhosis: characterization and role in acute-on-chronic liver failure. Hepatology 2016;64: 1249-1264.

47 Schierwagen R, Alvarez-Silva C, Madsen MSA, Kolbe CC, Meyer C, Thomas D, Uschner FE, Magdaleno F, Jansen C, Pohlmann A, Praktiknjo M, Hischebeth GT, Molitor E, Latz E, Lelouvier B, Trebicka J, Arumugam M: Circulating microbiome in blood of different circulatory compartments. Gut 2018;DOI: 10.1136/gutjnl2018-316227.
48 Yang AM, Inamine T, Hochrath $\mathrm{K}$, et al: Intestinal fungi contribute to development of alcoholic liver disease. J Clin Invest 2017;127:2829-2841.

49 Holland-Fischer P, Gronbaek H, Sandahl TD, Moestrup SK, Riggio O, Ridola L, Aagaard NK, Møller HJ, Vilstrup H: Kupffer cells are activated in cirrhotic portal hypertension and not normalised by TIPS. Gut 2011;60:1389-1393.

50 Lehmann JM, Claus K, Jansen C, Pohlmann A, Schierwagen R, Meyer C, Thomas D, Manekeller S, Claria J, Strassburg CP, Trautwein C, Wasmuth HE, Berres ML, Trebicka J: Circulating CXCL10 in cirrhotic portal hypertension might reflect systemic inflammation and predict ACLF and mortality. Liver Int 2018;38:875884 .

51 Trebicka J: Predisposing factors in acute-on-chronic liver failure. Semin Liver Dis 2016;36:167-173.

52 D'Amico G, Garcia-Tsao G, Pagliaro L: Natural history and prognostic indicators of survival in cirrhosis: a systematic review of 118 studies. J Hepatol 2006;44:217231.

53 Hernaez R, Sola E, Moreau R, Gines P: Acute-onchronic liver failure: an update. Gut 2017;66:541-553.

54 Costea PI, Hildebrand F, Arumugam M, et al: Enterotypes in the landscape of gut microbial community composition. Nat Microbiol 2018;3:8-16.

55 Vazquez-Baeza Y, Callewaert C, Debelius J, Hyde E, Marotz C, Morton JT, Swafford A, Vrbanac A, Dorrestein PC, Knight R: Impacts of the human gut microbiome on therapeutics. Annu Rev Pharmacol Toxicol 2018;58:253-270

56 Maier L, Pruteanu M, Kuhn M, Zeller G, Telzerow A, Anderson EE, Brochado AR, Fernandez KC, Dose H, Mori H, Patil KR, Bork P, Typas A: Extensive impact of non-antibiotic drugs on human gut bacteria. Nature 2018;555:623-628.

57 Llorente C, Jepsen P, Inamine T, et al: Gastric acid suppression promotes alcoholic liver disease by inducing overgrowth of intestinal Enterococcus. Nat Commun 2017;8:837.

58 Madsen BS, Trebicka J, Thiele M, Israelsen M, Arumugan M, Havelund T, Krag A: Antifibrotic and molecular aspects of rifaximin in alcoholic liver disease: study protocol for a randomized controlled trial. Trials 2018; 19:143.

59 European Association for the Study of the Liver: EASL clinical practice guidelines on the management of ascites, spontaneous bacterial peritonitis, and hepatorenal syndrome in cirrhosis. J Hepatol 2010;53:397-417.

60 Fernandez J, Navasa M, Planas R, Montoliu S, Monfort D, Soriano G, Vila C, Pardo A, Quintero E, Vargas V, Such J, Ginès P, Arroyo V: Primary prophylaxis of spontaneous bacterial peritonitis delays hepatorenal syndrome and improves survival in cirrhosis. Gastroenterology 2007;133:818-824

61 Moreau R, Elkrief L, Bureau C, et al: A randomized trial of 6-month norfloxacin therapy in patients with Child-Pugh class C cirrhosis. J Hepatol 2017;66:S1.

62 Kalambokis GN, Mouzaki A, Rodi M, Pappas K, Fotopoulos A, Xourgia X, Tsianos EV: Rifaximin improves systemic hemodynamics and renal function in patients with alcohol-related cirrhosis and ascites. Clin Gastroenterol Hepatol 2012;10:815-818.
63 Vlachogiannakos J, Viazis N, Vasianopoulou P, Vafiadis I, Karamanolis DG, Ladas SD: Long-term administration of rifaximin improves the prognosis of patients with decompensated alcoholic cirrhosis. J Gastroenterol Hepatol 2013;28:450-455.

64 Kimer N, Pedersen JS, Busk TM, Gluud LL, Hobolth L, Krag A, Møller S, Bendtsen F; Copenhagen Rifaximin (CoRif) Study Group: Rifaximin has no effect on hemodynamics in decompensated cirrhosis: a randomized, double-blind, placebo-controlled trial. Hepatology 2017;65:592-603.

65 Kimer N, Pedersen JS, Tavenier J, Christensen JE, Busk TM, Hobolth L, Krag A, Al-Soud WA, Mortensen MS, Sørensen SJ, Møller S, Bendtsen F; members of the CoRif study group: Rifaximin has minor effects on bacterial composition, inflammation, and bacterial translocation in cirrhosis: a randomized trial. J Gastroenterol Hepatol 2018;33:307-314.

66 O’Brien AJ, Fullerton JN, Massey KA, Auld G, Sewel G, James S, Newson J, Karra E, Winstanley A, Alazawi W, Garcia-Martinez R, Cordoba J, Nicolaou A, Gilroy DW: Immunosuppression in acutely decompensated cirrhosis is mediated by prostaglandin E2. Nat Med 2014;20:518-523.

67 Arroyo V, Moreau R: Tying up PGE2 with albumin to relieve immunosuppression in cirrhosis. Nat Med 2014;20:467-469.

68 Arroyo V, Garcia-Martinez R, Salvatella X: Human serum albumin, systemic inflammation, and cirrhosis. J Hepatol 2014;61:396-407.

69 Piano S, Schmidt HH, Ariza X, et al: Association between grade of acute on chronic liver failure and response to terlipressin and albumin in patients with hepatorenal syndrome. Clin Gastroenterol Hepatol 2018;DOI: 10.1016/j.cgh.2018.01.035.

70 Caraceni P, Pavesi M, Baldassarre M, Bernardi M, Arroyo $\mathrm{V}$ : The use of human albumin in patients with cirrhosis: a European survey. Expert Rev Gastroenterol Hepatol 2018:1-8.

71 Guevara M, Terra C, Nazar A, Sola E, Fernandez J, Pavesi M, Arroyo V, Ginès P: Albumin for bacterial infections other than spontaneous bacterial peritonitis in cirrhosis. A randomized, controlled study. J Hepatol 2012;57:759-765.

72 Thevenot T, Bureau C, Oberti F, et al: Effect of albumin in cirrhotic patients with infection other than spontaneous bacterial peritonitis. A randomized trial. J Hepatol 2015;62:822-830.

73 Caraceni P, Riggio O, Angeli P, et al: Long-term albumin administration improves survival in patients with decompensated cirrhosis: final results of the 'ANSWER' study. J Hepatol 2017;66:S93.

74 Fernandez J, Angeli P, Trebicka J, et al: Albumin administration in the prevention of hepatorenal syndrome (HRS) and death in patients with advanced cirrhosis and non-SBP infections. J Hepatol 2018;68 (suppl 1):S253-254. 